\title{
The Analysis and Reference for Western Urban Management System
}

\author{
Ji Wenyan ${ }^{1}$ \\ ${ }^{1}$ Department of Science and Technology and \\ Industrial Development, Beijing City University, \\ P. R. China \\ Liu Chengshui ${ }^{2}$ \\ ${ }^{1}$ Department of Science and Technology and \\ Industrial Development, Beijing City University, \\ P. R. China \\ ${ }^{2}$ Department of Scientific Research Administration, \\ Beijing City University, P. R. China
}

\begin{abstract}
The constant development of urbanization results in a large number of urban problems. Therefore, many cities in developed countries have made management system reform of different level in order to adapt to the development of the situation. To study and draw lessons from their reform methods and patterns, which will no doubt bring benefit to the present China's urban management system innovation. This paper selects some management modes of three cities including Tokyo, Baltimore and Columbia, some conclusion is obtained from three aspects consisting of government performance management improvement, cost savings and social supervision based on analysis.
\end{abstract}

Keywords: City Management;Experience of Western; Management Model

\section{Introduction}

Urban management system is a mode of power when a country organize, mobilize, manage and control a city's economic and social resources with political authority. It includes both the urban overall macro management system by the central government and the internal microscopic management system of a single city. Urban management system is a set of provisions of organization modes about urban management authority division and organization structure, which reflects the different period of economic and social development and government management capability maturity, is directly related to the efficiency and effect of urban management, is the most important factor of city management level. China is a government dominated society, whether the city system is scientific and reasonable, whether it can adapt to the needs of the development of the city, all these have direct impact on the efficiency of urban operation and its function, all these are key factor for scientific and sustainable development of the city. Scientific and rational urban system can promote the development and progress of the city; On the other hand, would hinder and lag its development. [2]

To clear the basic principles of city environment management system construction, We must widely draw on the successful experience of western city environment management system and learn wisdom.

\section{City Management Pattern in the West}

\subsection{Tokyo Model}

Firstly, Tokyo has long-term planning in urban management infrastructure, willing to invest big. It took Tokyo seven years to build a "common ditch" with total length of $16 \mathrm{~km}$ at a cost of 350 billion yen. This "common ditch" is the largest one in the world; which make full use of underground space with all kinds of infrastructure construction projects. "Common ditch" is an underground pipe well, which is 10 meters away from underground, 19 meters in width, and 5 meters in height. All the pipes of nine kinds of infrastructure such as water 
- supply pipe, middle water pipe, sewer pipe, gas pipe, electric cable, communication cable, and air conditioning cold heat pipe, garbage collection pipe are reasonably distributed, which avoids disorderly arrows and the phenomenon of chaos to dig the road. It is convenient for pipeline maintenance, so as to further perfect urban functions. In "Common ditch", the middle water pipe is used to reentry the waste water after sewage treatment, which effectively saves the water. Air conditioning cold heat pipes supply respectively cold water $\left(7{ }^{\circ} \mathrm{C}\right.$ to $15{ }^{\circ} \mathrm{C}$ ) and hot water $\left(50{ }^{\circ} \mathrm{C}\right.$ to $\left.80{ }^{\circ} \mathrm{C}\right)$, realizing the cooling and heating regionalization. Garbage collection tube will deliver the garbage debris to waste plant with a speed between 90 to 100 kilometers per hour. In order to prevent the earthquake damage to the "common ditch", the advanced pipes variant adjusting technology and rubber shock system are adopted. For new urban planning area, "common ditch" has become the ideal mode of modern urban infrastructure construction, and also provide a good foundation for the scientific city management.

Secondly, an environmental impact assessment system is set up in order to reduce the impact on the environment of city construction and operation. The system of environmental impact assessment of Tokyo plays an important role in the process of urban development. For any large city construction projects in the implementation stage, their impact on the environment after the completion of the project must be assessed. It is suggested to take corresponding measures to minimize the negative effect on the environment, the evaluation result should be published, opinions of the residents and the related local governments on the evaluation results should be discussed. The system of the Tokyo played an important role in metropolitan ecological environment protection and sustainable development of the city.

Thirdly, social forces outside the government are fully mobilized, which perfects the urban management of participation and supervision mechanism. The Tokyo government attaches great importance to all kinds of social forces active participation in the areas of urban environment management. Take the waste management for example, Tokyo government enacted the "basic regulations promoting circular society construction", which strengthen the responsibility of citizens and all kinds of social organizations from the source. Not only citizens must fulfill the environmental responsibility in daily life, reduce unnecessary waste; Enterprises and institutions must also perform "producers extension" in order to solve the problem of garbage in the process of product design and manufacturing, this will strengthen the environmental protection concept, make the product after using more convenient for recycling and resulting in less garbage. The maintenance of urban green space and public gardens heavily rely on the unofficial volunteers. The government set up a registration system for volunteers consisting of individuals and institutions and provided unified training program, guidance and management for them. In addition, in the environmental impact assessment system, the government set up a public feedback submission procedures, hearings should be held when necessary to discuss people's advice in the specific project environmental assessment. Information bulletin, opinion expression, supervision and feedback mechanism are established in many urban environmental construction fields, non-governmental force in urban management play an important role in these processes.

Fourth, the management system is of continuous flatter development. Tokyo has carried out administrative reform for five times since 1979; the main characteristic of the reform is to plan the organization and its function division continually and scientifically.

There is clear division between Tokyo and the district government in terms of functions, financial management and taxation. The Tokyo government is mainly responsible for the overall urban planning, the construction of sewage management, the construction of public housing, which is beyond the administrative range of district government; while the district government is responsible for handling all the regional affairs, and is closely related to the life of daily affairs, such as regional environment management, public welfare and living 
garbage collection processing, etc. In order to facilitate the coordination between the government and the district government and timely communication, Tokyo has also set up a permanent mechanism "Tokyo area agreements committee".[4]

The government management mode transformed from the bureaucracy or top-down "management" relying on regional segmentation in past, gradually to the "cooperative management" governance of various main switch among society, enterprises, and non-governmental organization. [5]

\subsection{Baltimore Model}

The city performance management project "CitiStat" pioneered by Baltimore city of USA is a typical representative of the modern western governance mode. This project is a kind of decision analysis, performance management and tracking evaluation relying on data driven, its aim is to detect problems timely, take remedial measures quickly and implement the process of whole operation performance supervision, which will improve the efficiency and quality of urban management and public service. CitiStat project is a set of urban operation data statistics system, data mainly comes from three aspects: 311 telephone service system, community liaison and government data report. [6]

The social supervision mechanism presented by the CitiStat project is established on the basis of western democratic system and community democratic autonomy, where the government consciously accept social supervision. In terms of economic costs, as of 2007 figures, CitiStat project implementation in seven years saved a total of about $\$ 350$ million for city operation cost. CitiStat project pay more attentions to the qualitative analysis on the basis of quantitative analysis such as continuous statistics evaluation, the link between decision making and data, setting up and achieving performance targets. [7]. The senior governments participate in CitiStat projects forcefully in order to avoid the lagging of management decisions. CitiStat meetings held once every two weeks are the center of the CitiStat project operation.
During the meeting, the mayor and the cabinet will be involved, many public service problems can be solved on the spot, and decisions can get timely implementation.

\subsection{Colombia Model}

The prominent characteristic of Columbia mode is urban management based on community, civil organizations is fully used for scientific management. Authorization by the government made the civil organizations to play a greater role in management. Colombia is a town located in Wade huo county, Maryland, USA. Its population is 100000 , and it covers an area of 56 square kilometers. In Columbia city, real management role is played by Columbia association. This is a completely an autonomous organization. Columbia association supplies special subsidies to the community associations.

The private Columbia association and Wade huo county government divided their own responsibility through contract. The county government is in charge of public security, fire control, basic education, garbage disposal, postal service, the main road construction and maintenance, street lamp, water supply and drainage, electricity and other public services and facilities maintenance. The rest of the public services, such as environmental protection, leisure fitness, parking service, pedestrian space construction and maintenance, pedestrian bridge construction and maintenance, all kinds of celebrations, etc., are borne by the association of Columbia, and the government gives corresponding financial support.

Columbia association manages, on a contract basis in Columbia, 3400 acres of public green space, 90 miles of the sidewalk, 1650 parking Spaces, 252 pedestrian Bridges, three large lakes and 20 small pond, 34 miles stream valley, 40 acres of symphony, Wilder and Elko lake park, etc. the source of funds include residents annual rental income, commercial rental income, income of community service projects. On spending for funds accounted for $69 \%$ of all spending on public services. 


\section{The comparative Analysis}

Three models enlighten us as the follows: These cities take operation environment management as strategic issues, and highlight the scientific status of environment management. In the process of implementing urban environment management, sufficient large-scale investment permanently solve some difficult problems in city management. Build a scientific and reasonable management system with the rule of law, technical support, and citizen participation. Due to the difference between our country's urban management system and the western urban management system in background of economic system and political system is different; the city management in our country has a different structure.

Firstly, the city management in our country also has the function of enterprise management, there is also has no clear difference between management and operation. The Mayor's first task is to grasp city planning, organize think tanks to help plan, and organize their implementation. Our country's city government is not only the organizer, but also the urban construction and urban management enforcement. The government has two roles both for construction and management, while urban management in the west separate government functions from enterprise management, it has perfect organization management structure, its power and responsibility is clear. The mayors realize the country's economic structure pattern in the concrete urban structure by the planning.

Secondly, our country's city management attaches great importance to the ideological education, an obvious rule by men. Western countries attaches great importance to the laws and regulations of urban management, legal consciousness is much stronger, government departments for city management administrate according to law. Departments varied with different functions, but they follow the same law of position and values. This reduces the internal friction, but also improves efficiency. City management under the national legal system consciousness has played a very important role to the development of western market economy.
Thirdly, the government of our country often plays the role of the "almighty government" in city management, which reflects the imperfection of the social development. Western countries is generally "civil society", where a large number of social intermediary organizations share the traditional function of the urban management, the typical mode of "small government, big society", the government only act as the role of the coaches and referees; Non-governmental non-profit organization plays an important role in community development, community volunteer organizations play a decisive role.

\section{Conclusions}

\subsection{Improve City Performance Management}

Urban management supervision (command) center is in the leading position of performance management system in the city. we should learn from this management ideas and apply it in the digital city management model to improve the importance of supervision (command) center in the whole city comprehensive management. As a result, the working mechanisms of digital urban management mode can realize truly orderly management, powerful coordination, and high efficiencies.

\subsection{Strengthen the Supervision of the Society}

Under the city information management system, it is an internal supervision mechanism to supervise and report issue by city supervisors; while it is an external supervision mechanism to reflect problems or complaints by citizen hotline. Both the external supervision and internal complaints can improve government performance; therefore, it should be equally attaching importance to them. In view of this, it is necessary to further broaden the social public participation channels, citizen complaints and comments should be brought into the government performance evaluation system so that citizens' calls can be effectively reflected in the government agenda. 


\subsection{Pay Attention to the economic Cost in the City Performance Management}

In the process of city management information system optimization and innovation, it is urgent to introduce urban management cost consciousness and take various means to save the city operation cost. This is the demand of city of performance management, also the demand of the whole society to build a conservation-minded government in a new era. On the basis of the implement of fine management, the economization and efficiency of urban management are not only the final destination for digital city management optimization development, but also a requirement for city managers with scientific development concept .

\section{References}

[1] Research on the environmental construction evaluation and its index system for the capital No.13JDCSD012

[2] Chen Sheng-yong, Yang Fu-yuan. 60 years of China's urban system changes and reform strategy. The social sciences. 2009 (80).
[3] James Canton, Overrun in the future, far flow publishing company, 2007.

[4] Zhang Guo-qing. During the period of "11th five-year plan" of Beijing urban management concept, system, mechanism research [M]. Beijing: Peking University press, 2010:200-201.

[5] Yang Li-xun.The world's advanced urban management research[M].China social sciences press,2009:58.

[6] Yang Hong-shan. A comparative study of urban performance management model - Beijing DUM mode and Baltimore City CitiStat project as an example[J] , Informational City Management.2010(5).

[7] Yang Hong-shan. Digital city management system analysis[J].Urban Studies 2009 (1). 